\title{
Loudness of tone pulses in a free field
}

\author{
Poulsen, Torben
}

\section{Published in:}

Acoustical Society of America. Journal

Link to article, DOI:

$10.1121 / 1.385915$

Publication date:

1981

\section{Document Version}

Publisher's PDF, also known as Version of record

Link back to DTU Orbit

\section{Citation (APA):}

Poulsen, T. (1981). Loudness of tone pulses in a free field. Acoustical Society of America. Journal, 69(6), 17861790. https://doi.org/10.1121/1.385915

\section{General rights}

Copyright and moral rights for the publications made accessible in the public portal are retained by the authors and/or other copyright owners and it is a condition of accessing publications that users recognise and abide by the legal requirements associated with these rights.

- Users may download and print one copy of any publication from the public portal for the purpose of private study or research.

- You may not further distribute the material or use it for any profit-making activity or commercial gain

- You may freely distribute the URL identifying the publication in the public portal

If you believe that this document breaches copyright please contact us providing details, and we will remove access to the work immediately and investigate your claim 


\title{
Loudness of tone pulses in a free field
}

\author{
Torben Poulsen \\ The Acoustics Laboratory. Technical University of Denmark. DK-2800 Lyngby, Denmark \\ (Received 17 September 1979; accepted for publication 19 February 1981)
}

\begin{abstract}
Investigations of temporal loudness summation of tone pulses have been performed. The investigations comprised equal loudness determinations between pairs of tone pulses with a duration ratio of 1:2, and threshold determinations of the same tone pulses. Pulse durations ranged from 5 to $640 \mathrm{~ms}$. The frequencies were 500,1000 , and $4000 \mathrm{~Hz}$. All pulses were shaped by means of $1 / 3$ octave filters. For 25 normal hearing observers the investigations were performed at the observer's threshold, and at 35 and $55 \mathrm{~dB} \mathrm{SPL}$. Fitting of the experimental data to a single exponential function yields a time constant $(\tau)$ of about 200 ms near and at the threshold, whereas $\tau$ is about $100 \mathrm{~ms}$ at levels well above threshold. Discrepancies exist, nevertheless, between this single-time-constant model and the experimental data obtained for the pulses of shortest duration. To account for this, a model is proposed comprising a combination of two exponential functions. This yields a short time constant of 5 to 10 ms combined with the longer time constant mentioned above.
\end{abstract}

PACS numbers: 43.66.Cb, 43.66.Mk, 43.66.Ba [BS]

\section{INTRODUCTION}

For brief sound stimuli the loudness depends very strongly on the duration of the stimuli. After the onset of a steplike stimulus the loudness will grow and after some time (less than $1 \mathrm{~s}$ ) reach a steady value. This phenomenon is called temporal integration or temporal loudness summation.

For many years research has been carried out in order to determine the relationship between the duration of the stimulus and auditory perception. The investigations may be divided into two groups:

(a) Threshold measurements performed either at the quiet or at a masked threshold, e.g., Garner and Miller (1947), Feldtkeller and Oetinger (1956), Plomp and Bouman (1959), Hempstock et al. (1964), Pedersen and Elberling (1972), Nábèlek (1978).

(b) Loudness balances and magnitude estimations performed at levels above threshold, e.g., Niese (1959), Port (1959), Zwicker (1966), Stevens and Hall (1966), Boone (1973), McFadden (1975).

This paper deals with temporal integration in a free field at threshold and at suprathreshold levels, evaluation of the description of the temporal integration by means of a time constant, and a model comprising two time constants.

\section{A. Models}

The time constant description of temporal integration is given by the relation

$$
I_{t} / I_{\infty}=1 /\left(1-e^{-t / \tau}\right) \text {. }
$$

The left side is the ratio between the intensities necessary to reach threshold-or to obtain equal loudnessfor a pulse of duration $t$, and for a long lasting pulse. The time constant is $\tau$. For $t \ll \tau$ Eq. (1) predicts that loudness can be maintained if a halving of the duration is compensated for by a doubling of the intensity, thus keeping the energy constant.

In the present investigation tone pulses of short duration are matched in loudness to pulses of double duration. The ratio between the two intensities at equal loudness is found by using Eq. (1) twice and eliminating $I_{\infty}$ :

$$
I_{t} / I_{2 t}=1+e^{-t / r} \text {. }
$$

For $t \ll \tau$ this ratio is almost equal to 2 . This means that a level difference of $3 \mathrm{~dB}$ must be expected for very short pulse durations.

Zwislocki's (1960) theory of temporal integration led to a time constant model. At the threshold of audibility, the time constant was found to be on the order of 200 ms. Above threshold the effective time constant decreased to about $100 \mathrm{~ms}$ (Zwislocki, 1969). The theory takes both psychophysical and neurophysiological factors into account. Especially the effect of the temporal decay of the neural firing rate makes it possible for the model to describe a variety of experimental data. For references and descriptions of other models see, e.g., Nábèlek (1978), Penner (1978), Ehret (1976), and Irwin and Kemp (1976).

\section{METHOD}

The measurements were performed at threshold and at 35 and $55 \mathrm{~dB}$ SPL, using 1000-Hz tone pulses. For the two levels above threshold $500-$ and $4000-\mathrm{Hz}$ tone pulses were also used. Combined with the levels from the international Round Robin Test on impulsive noise (Pedersen et al., 1977) the range was extended up to $95 \mathrm{~dB}$ SPL for $1000-\mathrm{Hz}$ tone pulses.

Apart from the threshold measurements all the measurements were performed as loundness balances between tone pulses of different durations. The signals were presented in pairs via a loudspeaker in an anechoic chamber. One of the two signals in the pair always had a duration twice the other. Thus a 20-ms pulse was compared in loudness with a $40-\mathrm{ms}$ pulse, a $40-$ ms with an 80-ms pulse, etc. This method reduces the difficulties for the observer and hence the variance in the results as pulses having this duration ratio sound more alike than pulses deviating very much in duration (Niese, 1956). 


\section{A. Apparatus}

The observers were seated in an anechoic chamber approximately $2 \mathrm{~m}$ from an electrostatic loudspeaker, QUAD. The tone pulses were generated by a programmable function generator, Wavetek 155, which was controlled by a PDP 8 minicomputer. The pulses were filtered in a $\frac{1}{3}$-octave filter, Brüel \& Kjær 1615. Their level was set by a computer-controlled Hewlett-Packard $350 \mathrm{D}$ attenuator.

\section{B. Signals}

Pulse durations were $5,10,20,40,80,160,320$, and $640 \mathrm{~ms}$. The pulses were generated from pure tones of 500, 1000, and $4000 \mathrm{~Hz}$. (A 5-ms duration was not used with the $500-\mathrm{Hz}$ tone pulses, because they would have been too close to threshold for some listeners. ) One-third octave filtering avoided clicks and kept the bandwidth within approximately one critical band.

In order to keep the energy content of the filtered pulse at the same level as for the unfiltered pulse, small corrections are necessary. The corrections were found by direct measurement (squaring and integration) and were, for $1000-\mathrm{Hz}$ tone pulses, $0.6 \mathrm{~dB}$ at $5 \mathrm{~ms}$ and $0.2 \mathrm{~dB}$ at $10 \mathrm{~ms}$. For longer durations the corrections were smaller. Corrections are included in the data presented here.

\section{Psychophysical method}

The two pulses in each pair were compared in loudness. The second pulse always had half the duration of the first one and was presented $500 \mathrm{~ms}$ after the end of the first pulse. After a pause of $2.5 \mathrm{~s}$ the same pair was presented again. This sequence was repeated until the observer gave one of three responses: (1) first pulse louder than second pulse, (2) equally loud, (3) second pulse louder than first pulse. The responses were given by means of push buttons and registered by the computer. After each response a pause of $10 \mathrm{~s}$ was inserted; the pulse pair was presented again, with the level of the second pulse changed. The computer was programmed to work in accordance with the Method of Maximum Likelihood (MML), (Lyregaard and Pedersen, 1971, 1974). This is a blas-free adaptive method where the most likely psychometric function is estimated after each new response from the observer. The presentation levels are chosen in order to obtain maximum efficiency by avoiding redundant presentations. Due to randomination it is impossiblefor the observer as well as for the investigator-to predict the course of the presentation levels. When the investigator sees that the estimation of the psychometric function has been stable during several responses, he stops the measurement. The results of a single loudness balance are typically based on about 20 evaluations.

It is assumed that the dependence of loudness on duration can be determined from loudness balances between tone pulses of 5 and 10,10 and 20,20 and 40,40 and 80,80 and 160,160 and 320 , and 320 and $640 \mathrm{~ms}$. These balances were performed in a random order.

For the threshold measurements the MML procedure was slightly modified. The tone pulse was presented up to 5 times in a row at $500-\mathrm{ms}$ intervals. The observer pressed a button as soon as he heard the pulse; the computer generated-after $2 \mathrm{~s}-\mathrm{a}$ "not heard" response if the observer had not pressed the button. The observer did not know in advance when the pulses were presented.

\section{Observers}

Twenty-five observers were paid to participate in the measurements. They were male students between 17 and 22 years old from the Technical University of Denmark. Hearing thresholds were within $10 \mathrm{~dB}$ of normal (ISO 389 ), except that a hearing loss of $15 \mathrm{~dB}$ at a single frequency was allowed. For $1000 \mathrm{~Hz}$ only $10 \mathrm{~dB}$ was allowed. In some measurement serles only some of the observers participated (see Table I).

\section{RESULTS}

Figure 1 shows the results for $1000-\mathrm{Hz}$ tone pulses, and Fig. 2 shows the results for $500-$ and $4000-\mathrm{Hz}$ tone pulses. As a function of pulse duration, the figures show equal loudness curves at different levels. The results at 1000 and $4000 \mathrm{~Hz}$ are quite similar, whereas the results at $500 \mathrm{~Hz}$ differ somewhat from the others at the $35-\mathrm{dB}$ level.

Figure 3 shows data from the loudness balances at $1000 \mathrm{~Hz}, 35 \mathrm{~dB}$ SPL. Each data point shows the level difference necessary to obtain equal loudness for the

TABLE I. Estimated time constants yielding best fit by the method of least squares. Model comprising a single time constant (left) and model comprising two time constants (right). The fit may be evaluated by the sum of squared deviations, SSD.

\begin{tabular}{|c|c|c|c|c|c|c|c|}
\hline \multirow{2}{*}{$\begin{array}{c}\text { Frequency } \\
\mathrm{Hz}\end{array}$} & \multirow{2}{*}{$\begin{array}{c}\text { Level } \\
\text { dB SPL }\end{array}$} & \multirow{2}{*}{$\begin{array}{c}\text { No. of } \\
\text { observerg }\end{array}$} & \multicolumn{2}{|c|}{ Single time constant } & \multicolumn{3}{|c|}{ Two time constants } \\
\hline & & & $\mathrm{T}, \mathrm{ms}$ & $\mathrm{SSD}, \mathrm{dB}^{2}$ & $\tau_{1}, \mathrm{~ms}$ & $\tau_{2}, \mathrm{~ms}$ & $\mathrm{SSD}, \mathrm{dB}^{2}$ \\
\hline 500 & 35 & 12 & 110 & 2.2 & $\ldots$ & $\ldots$ & ... \\
\hline 500 & 55 & 12 & 50 & 2.6 & $\cdots$ & $\ldots$ & . \\
\hline 1000 & threghold & 25 & 220 & 3.3 & 4 & 210 & 1.6 \\
\hline 1000 & 35 & 11 & 320 & 10.3 & 14 & 280 & 0.3 \\
\hline 1000 & 55 & 11 & 110 & 2.6 & 4 & 100 & 1.3 \\
\hline 4000 & 35 & 9 & 240 & 6.4 & 8 & 220 & 0.9 \\
\hline 4000 & 55 & 12 & 100 & 2.5 & 4 & 100 & 0.7 \\
\hline
\end{tabular}




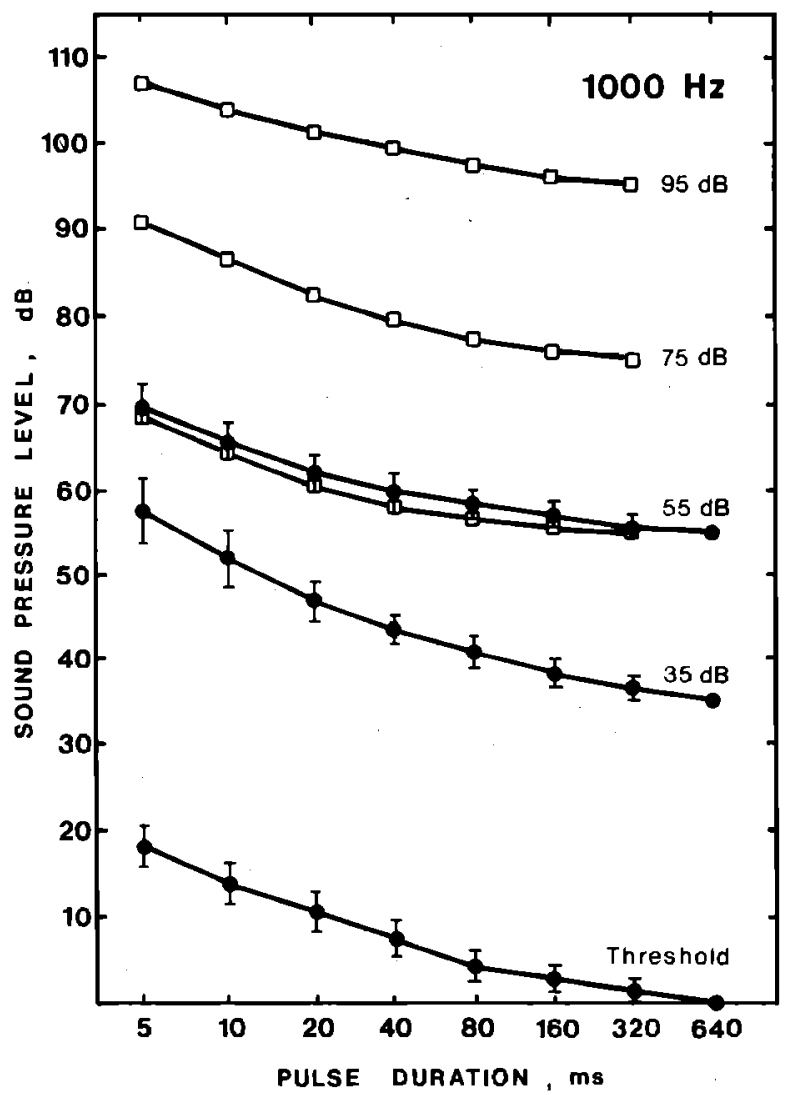

FIG. 1. Temporal integration of $1000-\mathrm{Hz}$ tone pulses. Level is parameter. Filled circles are from the present investigation. Open squares are from the international Round Robin Test on impulsive noise. $95 \%$ confidence intervals are shown.

two pulses in a pair. The solid curve is the theoretical exponential function with a time constant of approximately $\tau=300 \mathrm{~ms}$ [Eq. (2)], and the asymptotic value of $3 \mathrm{~dB}$ (constant energy principle) is easily recognized. The "correct" time constant is found by shifting this

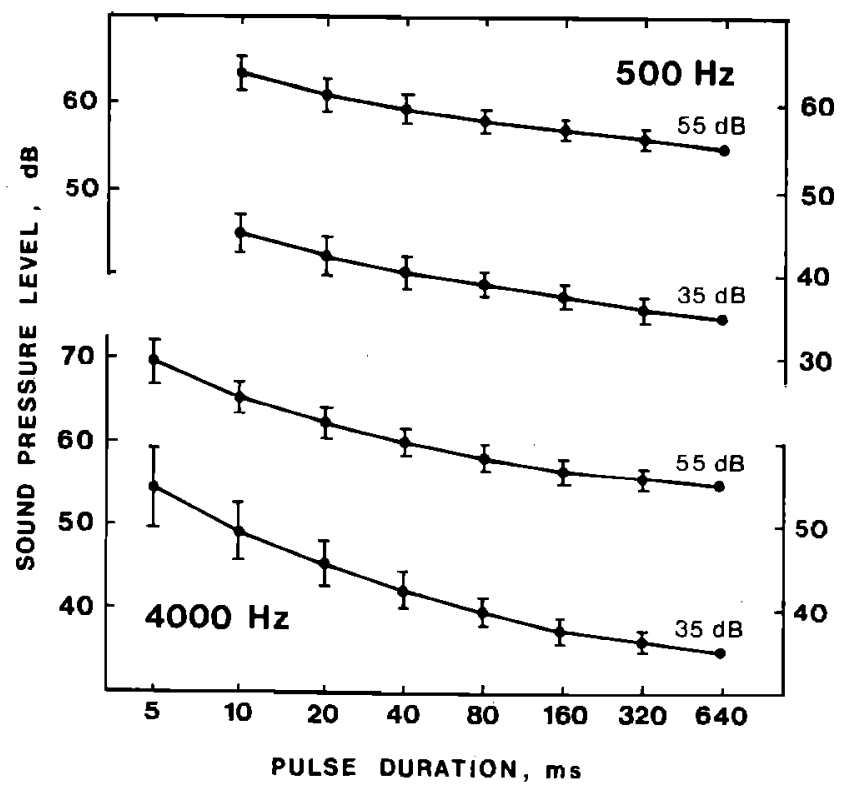

FIG. 2. Temporal integration of $500-\mathrm{Hz}$ tone pulses (upper curves) and of $4000-\mathrm{Hz}$ tone pulses (lower curves). 95\% confidence intervals are shown.

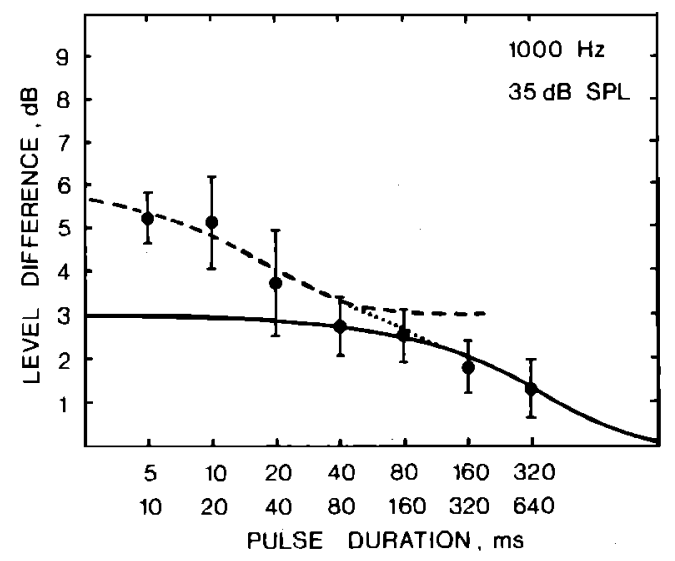

FIG. 3. Loudness balance of tone pulses baving a duration ratio of $1: 2$. (By accumulating these data the $35-\mathrm{dB}$ curve in Fig. 1 is achieved.) Solid curve shows an exponential model with a time constant $\tau \simeq 300 \mathrm{~ms}$. For the shortest pulses the data exceeds $3 \mathrm{~dB}$ resulting in a slope of the integration curve steeper than $-3 \mathrm{~dB}$ per doubling of duration. If a short-time constant (dashed) is combined with a long-time constant (solld) the data exceeding $3 \mathrm{~dB}$ may be described. The combined model is shown dotted in the midrange.

curve along the abscissa until the best fit between curve and data is obtained. It is evident that no matter how much the curve is shifted along the abscissa the data for the shortest durations will never be reached as they exceed $3 \mathrm{~dB}$. Despite these limitations in the fitting, time constants have been estimated (method of least squares) and are shown in Table I. In order to illustrate the discrepancies between the data points and the theoretical exponential curve, the sum of squared deviations (SSD) is also given. The data in the time constant estimation were mean values over subjects.

Since a better fitting is achieved by increasing the number of parameters in the model, two time constants are proposed. The expression is given in Eq. (3).

$$
I_{t} / I_{2 t}=\left(1+e^{-t / \tau_{1}}\right)\left(1+e^{-t / \tau_{2}}\right) .
$$

The additional time constant in this model is schematically shown by the dashed curve in Fig. 3. The time constants obtained by means of this double exponential function are also shown in Table $I$. As the 5-ms pulse was omitted at $500 \mathrm{~Hz}$ the estimation of the short-time constant is of no significance at this frequency. By comparing the SSD's given in Table $I$ it is seen that a much better description is achieved by a model comprising two time constants.

\section{DISCUSSION}

For the $1000-\mathrm{Hz}$ tone pulses it is possible to compare the data obtained in the ISO Round Robin Test on impulsive noise (Pedersen et al., 1977). In that investigation approximately 300 observers distributed over 21 laboratories from all over the world participated. The aim was to find objective methods for measuring the loudness level of impulsive sounds, which would correlate well with subjective measurements. Besides loudness measurements of impulsive sounds in daily life, loudness balances of the same filtered $1000-\mathrm{Hz}$ 
TABLE II. As Table I, but data from international Round Robin Test on Impulsive noise.

\begin{tabular}{|c|c|c|c|c|c|c|}
\hline \multirow{2}{*}{$\begin{array}{c}\text { Frequency } \\
\mathrm{Hz}\end{array}$} & \multirow{2}{*}{$\begin{array}{c}\text { Level } \\
\text { dB SPL }\end{array}$} & \multicolumn{2}{|c|}{ Single time constant } & \multicolumn{3}{|c|}{ Two time constants } \\
\hline & & $\tau, \mathbf{m s}$ & $\mathrm{SSD}, \mathrm{dB}^{2}$ & $\tau_{1}, \mathrm{~ms}$ & $\tau_{2,} \mathrm{~ms}$ & $\mathrm{SSD}, \mathrm{dB}^{2}$ \\
\hline 1000 & 55 & 80 & 6.4 & 10 & 50 & 0.6 \\
\hline 1000 & 75 & 120 & 6.2 & 8 & 90 & 0.4 \\
\hline 1000 & 95 & 80 & 0.8 & 2 & 80 & 0.6 \\
\hline
\end{tabular}

tone pulses, as reported here, were performed at 55 , 75, and $95 \mathrm{~dB}$ SPL. The results are shown in Fig. 1 by the unfilled squares. The curves obtained at $55 \mathrm{~dB}$ in the Round Robin Test and in the present investigation are in good agreement. Table II shows-for the Round Robin Test data-the estimated time constant In a single-constant model. It is seen that only at the highest level (95 dB SPL) is this model able to describe the data reasonably well. Fitting the same data to a model with two time constants yields the results also shown in Table $\Pi$. At 55 and $75 \mathrm{~dB}$, the reduction in the sum of squared deviations is considerable.

The threshold data are in good agreement with previous data (e.g. , Hempstock et al., 1964; Pedersen and Elberling, 1972). For $1000 \mathrm{~Hz}$ the time constant is $220 \mathrm{~ms}$ at threshold (single-constant model, Table I), whereas it is $110 \mathrm{~ms}$ at $55 \mathrm{~dB} \mathrm{SPL}$. The time constants are close to those from Zwislocki's model (1960, 1969). (Threshold measurements were not performed for 500 and $4000 \mathrm{~Hz}$, but the time constant did tend to decrease at higher levels.)

A discrepancy is often found between the values predicted by the single-time-constant model and the experimental data at the shortest pulse durations, below 20 to $30 \mathrm{~ms}$. For these short pulses the slope of the curve is steeper than $-3 \mathrm{~dB}$ per doubling of duration. To overcomes this problem, Watson and Gengel (1969) took only three durations $(32,64$, and $128 \mathrm{~ms}$ ) into account when they computed the time constant, whereas Plomp and Bouman (1959) suggested a frequency-dependent correction to the model. The data reported here suggest level differences between 0 and $2 \mathrm{~dB}$ at durations longer than $40 \mathrm{~ms}$, and between 2 and $5 \mathrm{~dB}$ at durations shorter than $40 \mathrm{~ms}$. Accordingly, the model with two time constants was developed to permit a slope steeper than $-3 \mathrm{~dB}$ per doubling of duration for the shortest pulses.

This model qualitatively separates the time domain into three intervals: durations shorter than $\tau_{1}$, durations between $\tau_{1}$ and $\tau_{2}$, and durations longer than $\tau_{2}$. This separation into time intervals is qualitatively in accordance with Zwicker $(1973 ; 1974)$. He finds three characteristic durations in the hearing mechanism: 2, 20 , and $200 \mathrm{~ms}$. His results are based on different experiments which are not solely concerned with temporal integration. Zwicker states that the three values are valid for the hearing mechanism as such, but that the values may deviate by a factor of 2 towards larger or smaller values is quite possible.

Green et al. (1957) suggested that the temporal integration curve could be approximated by three intersect-
Ing lines with different slopes. At that time the increased slope ( $-4.5 \mathrm{~dB}$ per doubling of duration) used for pulse durations shorter than $15 \mathrm{~ms}$ was acribed to the increased bandwidth of these short pulses. Owing to the filter used in all the present measurements this spectral explanation is not valid here. For practical purposes, the very simple approximation by means of three straight lines could, on the other hand, yield an adequate description of the integration curve.

Baru (1971) has investigated the tone-pulse thresholds of dogs. Removal of the auditory cortex increases the threshold for pulse durations less than approximately $20 \mathrm{~ms}$. Partly based on these results, he suggests that the hearing mechanism has a short time constant of 20 to $40 \mathrm{~ms}$ and a long constant of 100 to $200 \mathrm{~ms}$.

\section{CONCLUSION}

From the results reported here it must be concluded that the single time-constant model cannot describe the experimental data adequately. This is mainly because level differences greater than $3 \mathrm{~dB}$ per doubling of duration are found for the shortest pulses (less than 20 to $40 \mathrm{~ms}$ ), and thus the slope is steeper than predicted by the time-constant model. A model comprising a combination of two time constants is, on the other hand, able to reproduce the steeper slope of the curve at short durations. The short-time constant is 5 to 10 ms whereas the long-time constant is about $200 \mathrm{~ms}$ near threshold and about $100 \mathrm{~ms}$ at levels well above threshold.

\section{ACKNOWLEDGMENTS}

The work has been made possible by a grant from the Danish Government Foundation for Scientific and Industrial Research. Associate Professor O. Juhl Pedersen is kindly acknowledged for inspiration and valuable discussions during this work.

Baru, A. V. (1971). "Absolute thresholds and frequency difference limen as a function of sound duration in dogs deprived of the auditory cortex," in Sensory Processes at the Neuronal and Behavioural Levels, edited by G. V. Gersuni (Academic, New York/London), pp. 265-285.

Boone, M. M. (1973). "Loudness measurements on pure tone and broad band impulsive sounds," Acustica 29, 198-204.

Ehret, G. (1976). "Temporal auditory summation for pure tones and white noise in the house mouse (mus musculus)," J. Acoust. Soc. Am. 59, 1421-1427.

Feldtkeller, R., and Oetínger, R. (1956). "Die Hörbarkeitsgrenzen von Impulsen verschiedener Dauer," Acustica 6, 489-493.

Garner, W. R., and Miller, G. A. (1947). "The masking 
threshold of pure tones as a function of duration," J. Exp. Psych. 37, 293-303.

Green, D. M., Birdsall, T. G., and Tanner, P. W., Jr. (1957). "Signal detection as a function of signal intensity and duration," J. Acoust. Soc. Am. 29, 523-531.

Hempstock, T. I., Bryan, M. E., and Tempest, W. (1964). "A redetermination of quiet thresholds as a function of stimulus duration," J. Sound Vib. 1, 365-380.

Irwin, R. J., and Kemp, S. (1976). "Temporal summation and decay in hearing," J. Acoust. Soc. Am. 59, 920-925.

Iyregaard, P. E., and Pedersen, O. J. (1971). "Application of a digital computer for subjective measurements," in Proceedings of 7 th I.C.A. (Akademia Kiado, Budapest), Vol. 3, pp. 669-672.

Lyregaard, P. E., and Pedersen, O. J. (1974). "Loudness level of impulsive noise," Rep. No. 6, The Acoustics Laboratory. Technical University of Denmark, pp. 1-68.

McFadden, D. (1975). "Duration-intensity reciprocity for equal loudness," J. Acoust. Soc. Am. 57, 702-704.

Nábélek, I. V. (1978). "Temporal summation of constant and gliding tones at masked auditory threshold," J. Acoust. Soc. Am. 64, 751-763.

Niese, H. (1956). "Vorschlag für de Definition und Messung der Deutlichkeit nach subjektiven Grundlagen," Hochfrequenztech. Elektroakust. 65, 4-15.

Niese, H. (1959). "Die Trägheit der Lautstarkebildung in Abhänglgkeit vom Schallpegel," Hochfrequenztech. Elektroakust. 68, 143-152.

Pedersen, C. B., and Elberling, C. (1972). "Temporal integration of acoustic energy in normal hearing persons," Acta Oto-Laryngol. 74, 398-405.
Pedersen, O. J., Lyregaard, P. E., and Poulsen, T. (1977). "The round robin test on impulsive noise," Rep. No. 22, The Acoustics Laboratory. Technical University of Denmark, pp. $1-180$.

Penner, M. J. (1978). "A power law transformation resulting in a class of short-term integrators that produce time-intensity trades for noise bursts," J. Acoust. Soc. Am. 63, 195201.

Plomp, R., and Bouman, B. A. (1959). "Relation between hearing threshold and duration for tone pulses," J. Acoust. Soc. Am. 31. 749-758.

Port, E. (1959). "Die Lautstärke von Tonimpulsen verschiedener Dauer," Frequenz 13, 242-245.

Stevens, J. C., and Hall, J. W. (1966). "Brightness and loudness as functions of stimulus duration," Percept. Psychophys. 1, 319-327.

Watson, C. S., and Gengel, R. W. (1969). "Signal duration and signal frequency in relation to auditory sensitivity," $\mathrm{J}$. Acoust. Soc. Am. 46, 989-997.

Zwicker, E. (1966). "Ein Beitrag zur Lautstärkemessung impulshaltiger Schalle," Acustica 17, 11-22.

Zwicker, E. (1973). "Temporal effects in psychoacoustical excitation," in Basic Mechanisms in Hearing, edited by $\AA$. R. Moller (Academic, New York/London), pp. 809-824.

Zwicker, E. (1974). "Time constant (characteristic durations) of hearing," J. Audiol. Tech. 13, 82-102.

Zwislocki, J. (1960). "Theory of Temporal Auditory Summation,” J. Acoust. Soc. Am. 32, 1046-1060.

Zwislocki, J. (1969). "Temporal Summation of Loudness: An Analysis," J. Acoust. Soc. Am. 46, 431-441. 